\title{
A novel nonsense mutation in the sedlin gene $(S E D L)$ causes severe spondyloepiphyseal dysplasia tarda in a five-generation Chinese pedigree
}

\author{
X.Y. Xia ${ }^{1 *}$, J. Yu ${ }^{2 *}$,W.W. Li ${ }^{1 *}$, N. Li ${ }^{1}$, Q.Y. Wu ${ }^{1}$, X. Zhou ${ }^{1}$, Y.X. Cui ${ }^{1}$ \\ and X.J. Li ${ }^{1}$ \\ ${ }^{1}$ Institute of Laboratory Medicine, Jinling Hospital, \\ Nanjing University School of Medicine, Nanjing, China \\ ${ }^{2}$ Department of Orthopaedics, Jinling Hospital, \\ Nanjing University School of Medicine, Nanjing, China \\ *These authors contributed equally to this study. \\ Corresponding authors: X.-J. Li / Y.X. Cui \\ E-mail: lixiaojun1962@gmail.com / cuiyingxia55@gmail.com
}

Genet. Mol. Res. 13 (2): 3362-3370 (2014)

Received January 24, 2013

Accepted July 19, 2013

Published April 29, 2014

DOI http://dx.doi.org/10.4238/2014.April.29.15

\begin{abstract}
Spondyloepiphyseal dysplasia tarda (SEDT) is an X-linked recessive osteochondrodysplasia characterized by disproportionately short stature and degenerative joint disease. The objective of this study was to describe a novel nonsense mutation in the sedlin gene $(S E D L)$ causing severe SEDT in a large Chinese pedigree. The clinical features of all affected individuals and female carriers were presented. Four affected males of the family were diagnosed with SEDT according to their clinical and radiological features. Direct DNA sequencing of SEDL was performed. Reversetranscription polymerase chain reaction (RT-PCR) experiments of
\end{abstract}


total RNA from blood lymphocytes were performed to confirm the defect in $S E D L$. DNA sequencing revealed that all of the affected males carried a nonsense mutation $($ c. $61 \mathrm{G}>\mathrm{T})$ in $S E D L$ that has not been previously reported. The c. $61 \mathrm{G}>\mathrm{T}$ mutation resulted in a premature translation termination codon $(\mathrm{GAG}>\mathrm{TAG})$ at amino acid position 21 (p.E21*), and was predicted to initiate the degradation of mutant transcripts through the nonsense-mediated mRNA decay pathway. Two female carriers showed typical sequencing chromatograms of a heterozygote. Following genetic counseling, individual IV7 gave birth to a healthy baby. Therefore, identification of the novel nonsense mutation (c.61G>T) in the SEDT family enables carrier detection, genetic counseling, and prenatal diagnosis. The detailed genotype/phenotype descriptions contribute to the $S E D L$ mutation spectrum. The continued identification of mutations in SEDT patients will greatly aid further elucidation of the role of the sedlin protein in normal bone growth.

Key words: Spondyloepiphyseal dysplasia tarda; $S E D L$ gene; Nonsense mutation

\section{INTRODUCTION}

Spondyloepiphyseal dysplasia tarda (SEDT; MIM 313400) is an X-linked skeletal disorder characterized by short stature, a short trunk, and precocious osteoarthritis (Gedeon et al., 1999; Savarirayan et al., 2003). The condition is not evident at birth, but rather presents most commonly after the first decade of life. Diagnosis is usually based on the characteristic vertebral body dysplasia, comprising platyspondyly and a central hump (Mumm et al., 2000; Christie et al., 2001). The causative gene of SEDT was successfully identified in 1999 and was designated as SEDL (Gedeon et al., 1999). SEDL consists of six exons that span approximately $22 \mathrm{~kb}$ of genomic DNA and encodes a 140 amino acid protein, sedlin (Savarirayan et al., 2003). The function of sedlin has not been well-established, but recent studies have postulated that it may play a role in the compartments involved in vesicular transport from the endoplasmic reticulum (ER) to the Golgi (Jang et al., 2002; Liu et al., 2010; Zong et al., 2011). The 420-bp coding region of SEDL is organized into four exons (exon 3 to exon 6) and three introns. The non-coding exons consist of exons 1 and 2, the 5' portion of exon 3, and the 3' portion of exon 6 (Gecz et al., 2003). More than 40 different $S E D L$ mutations have been described in various ethnic groups since the gene was first identified; however, genotype-phenotype correlations for $S E D L$ mutations remain unknown (Gedeon et al., 2001; Grunebaum et al., 2001; Mumm et al., 2001; Shaw et al., 2003; Fiedler et al., 2004; Xia et al., 2009). In the present study, we report a novel nonsense mutation in SEDL that causes severe SEDT in a large Chinese pedigree. Molecular genetic testing of the $S E D L$ gene enables carrier detection and presymptomatic/prenatal diagnosis for SEDT. Identification of the novel mutation will also be useful for understanding the molecular mechanisms underlying SEDT. 


\section{MATERIAL AND METHODS}

\section{Clinical report}

The present study was approved by the Institutional Review Board of Nanjing University Medical Center, and informed consent was obtained from all participants. A 30 -year-old Chinese male of short stature (case IV20, the proband) was referred for genetic counseling because of our recent achievements in the molecular diagnosis of genetic skeletal dysplasia (Xia et al., 2007; Cui et al., 2008; Xia et al., 2008a,b). Upon examination, his height was $147 \mathrm{~cm}$ (25th percentile), and his arm span was $165 \mathrm{~cm}$; his trunk was disproportionately short, and his chest was barrel-shaped. The patient complained of moderate pain in weight-bearing joints and mild back pain. Facial features were unremarkable, and the results of neurological examination were within normal limits. Short stature was noted in late childhood (age 10). Serum concentrations of growth hormone and thyroid hormone were normal. Radiography of the lumbar vertebrae and epiphyses revealed the typical characteristic features of SEDT. Platyspondyly with hump-shaped central portions of the vertebral bodies was noted, and the epiphyses were irregular with flattening of the femoral heads (Figure 1). Family history also revealed five other affected males on the maternal side. The five-generation Chinese SEDT pedigree is shown in Figure 2. There was no male-to-male transmission of the short stature phenotype, suggesting an X-linked recessive mode of inheritance. The diagnosis of SEDT was based on radiological features and on the inheritance pattern of the family.

Clinical features of all of the affected individuals and female carriers in the SEDT family are summarized in Table 1 . Affected male family members appeared to show a severe clinical condition, with disproportionate short-trunked short stature, hip or back

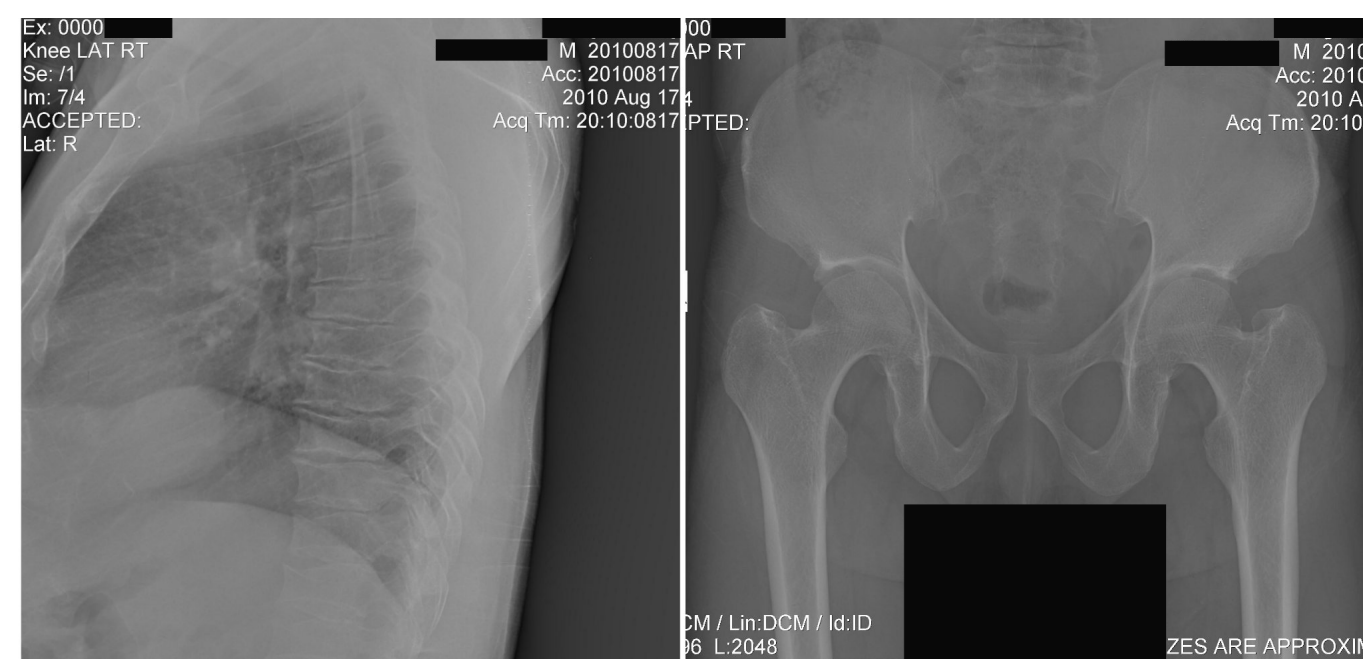

Figure 1. Radiographs of the lateral lumbosacral spine (left) and pelvis (right) of the proband (case IV5) from the large Chinese SEDT pedigree. Radiographs revealed platyspondyly with superior and inferior humping of the vertebral bodies; the pelvis was somewhat narrow, and the femoral necks were short. 
pain, and obvious evidence of thoracolumbar scoliosis. The female carrier in the pedigree (III16) complained of mild joint pain. Three individuals in the family (IV7, IV10, and IV11), who were at-risk SEDT female carriers, wanted to have molecular genetic testing before pregnancy. All individuals who participated in the study were provided with extensive genetic counseling before testing.

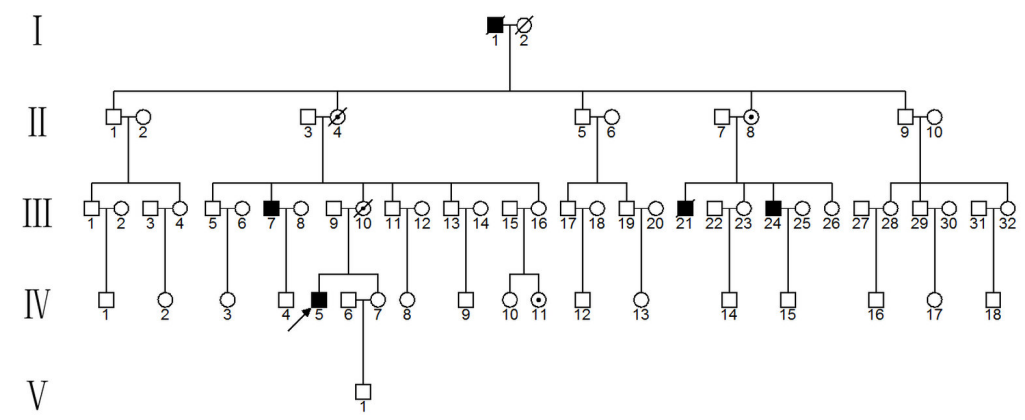

Figure 2. Pedigree of a large Chinese SEDT family. The arrow indicates the proband (IV5). All open boxes represent healthy males and open circles represent healthy females. Filled boxes represent affected males. Boxes or circles with a crossing line indicate that the person has already died. All circles with a dot in the middle indicate the status of carrier.

Table 1. Clinical features of all affected individuals and female carriers in the SEDT family.

\begin{tabular}{|c|c|c|c|c|c|c|c|c|c|c|}
\hline Cases & Gender & $\begin{array}{l}\text { Age } \\
(\mathrm{yr})\end{array}$ & $\begin{array}{c}\text { Onset } \\
\text { (yr) }\end{array}$ & $\begin{array}{l}\text { Adult height } \\
(\mathrm{cm})\end{array}$ & $\begin{array}{l}\text { Arm span } \\
(\mathrm{cm})\end{array}$ & $\begin{array}{l}\text { Back } \\
\text { pain }\end{array}$ & $\begin{array}{l}\text { Hip } \\
\text { pain }\end{array}$ & $\begin{array}{l}\text { Barrel } \\
\text { chest }\end{array}$ & $\begin{array}{l}\text { Thoracolumbar } \\
\text { scoliosis }\end{array}$ & Platyspondyly \\
\hline \multicolumn{11}{|l|}{ Patient No. } \\
\hline Proband (IV5) & M & 30 & 10 & 147 & 165 & Mild & Moderate & Yes & Moderate & Mild \\
\hline III7 & M & 58 & 8 & 138 & 162 & Severe & Severe & Yes & Severe & Severe \\
\hline III13 & M & 54 & 9 & 140 & 163 & Severe & Severe & Yes & Severe & Severe \\
\hline III 24 & M & 39 & 10 & 143 & 167 & Moderate & Severe & Yes & Severe & Moderate \\
\hline \multicolumn{11}{|l|}{ Carrier No. } \\
\hline III16 & F & 53 & No & 165 & 163 & No & Mild & No & No & No \\
\hline IV11 & F & 24 & No & 169 & 166 & No & No & No & No & No \\
\hline
\end{tabular}

\section{DNA sequencing}

Blood samples were obtained with informed consent from the five affected individuals (except I1, who was deceased), 58 unaffected relatives of the family, and 200 controls (unrelated healthy subjects, 100 males and 100 females). Genomic DNA was extracted from blood samples using the Wizard ${ }^{\mathrm{TM}}$ Genomic DNA Purification Kit (Promega, Madison, WI, USA) according to manufacturer instructions, and was stored at $-80^{\circ} \mathrm{C}$. In each subject, exons $3,4,5$, and 6 (containing the coding sequence) of $S E D L$ and adjacent splice sites were amplified by polymerase chain reaction (PCR) under the following conditions: $95^{\circ} \mathrm{C}$ for $5 \mathrm{~min}$ followed by 35 cycles of $94^{\circ} \mathrm{C}$ for $30 \mathrm{~s}, 56^{\circ} \mathrm{C}$ for $30 \mathrm{~s}$, and $72^{\circ} \mathrm{C}$ for $60 \mathrm{~s}$. The specific primer pairs are listed in Table 2. PCR products were sequenced in both directions and sequencing reactions were performed using the Big-Dye terminator sequencing kit and an ABI 3730 automated sequencer. All of the sequences were compared with the normal sequences in the National Center for Biotechnology Information (NCBI) database. 


\section{Reverse transcription (RT)-PCR experiments}

RT-PCR experiments were performed to further confirm the defect in the SEDL gene. Total RNA from blood lymphocytes was extracted using Trizol reagent (Invitrogen, USA). RNA integrity was confirmed by direct visualization of the $18 \mathrm{~S}$ and $28 \mathrm{~S}$ rRNA bands after agarose gel electrophoresis. The purified $0.5 \mathrm{mg}$ RNA samples were then reverse-transcribed using the SuperScript first-strand synthesis system (Invitrogen) and oligo-dT18. Subsequently, PCR was performed using the primers listed in Table 2. RT-PCR products were sequenced in both directions.

\begin{tabular}{llc}
\multicolumn{2}{l}{ Table 2. Primer sequences for amplying $S E D L$ gene. } & \\
\hline Fragments & Primers $\left(5^{\prime} \rightarrow 3^{\prime}\right)$ & PCR products (bp) \\
\hline Exon 3 & F: GAATTCTACACTTCCCATTAGTC & 265 \\
Exon 4 & R: TATCTGTCCAGATCTTCCAGTTC & 289 \\
Exon 5 & F: GCAAATGTTAATCTGTGGTTGC & 203 \\
& R: TGACTGTGAAGTCTACAGACT & 203 \\
Exon 6 & F: TACTGTATCAACGAACTGGTTG & 326 \\
CDNA & R: GTCGAATCCTTTCTCATCAGAA & 326 \\
& F: CAGAAACTTAAGATTTGTCAGC & 600 \\
\hline
\end{tabular}

\section{RESULTS}

Genomic DNA sequencing of all affected males in this family revealed a single nucleotide substitution (c.61G>T) in exon 3 of $S E D L$. The c.61G $>$ T mutation creates a premature termination codon $(\mathrm{GAG}>\mathrm{TAG})$ at amino acid position 21 (p.Glu21Stop, p.E21*), which is predicted to initiate degradation of mutant transcripts through the nonsense-mediated mRNA decay (NMD) pathway. The nonsense mutation (c. $61 \mathrm{G}>\mathrm{T}$ ) appeared to be novel, as it has not been previously reported in the literature or databases.

The sequencing chromatograms of two females (III16 and IV11 in Figure 2) were shown to be heterozygous for the substitution, confirming their carrier status. Therefore, individual IV11 would be at risk of having children affected with SEDT, whereas individuals IV7 and IV10 would not. Following genetic counseling, IV7 has since given birth to a healthy baby.

No other sequence changes were observed in the coding region or flanking intronic sequences of the members of the family, and the c. $61 \mathrm{G}>\mathrm{T}$ mutation was not found in the 200 healthy control subjects tested. The nonsense mutation (c.61G>T) identified in $S E D L$ is illustrated in the schematic diagram (Figure 3A), and the typical sequencing chromatograms of a healthy control, an SEDT patient, and a female carrier are shown in Figure 3B, C, and D, respectively. The above genomic DNA sequencing results were confirmed by RT-PCR experiments. RT-PCR sequencing results are shown in Figure S1.

\section{DISCUSSION}

$\mathrm{X}$-linked SEDT is a rare disease with an estimated prevalence of 1.7 per $1,000,000$ individuals (Xia et al., 2009). Various types of mutations in the SEDL gene, including dele- 


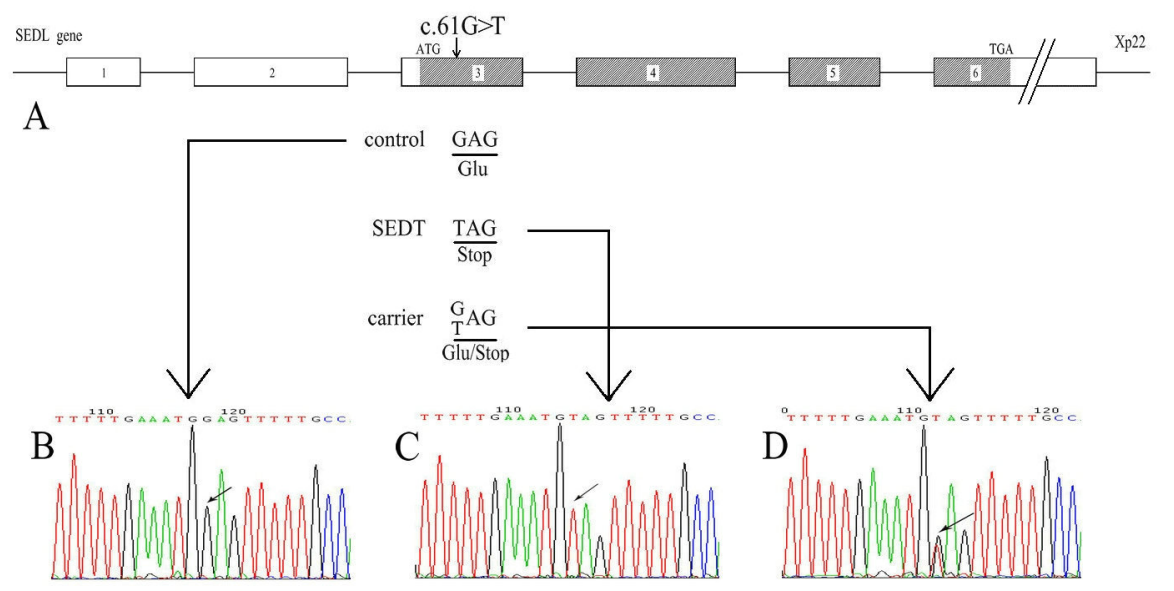

Figure 3. Nonsense mutation (c.61G $>$ ) ) identified in the family is illustrated in the schematic diagram (A). The human $S E D L$ gene consists of six exons that span approximately $20 \mathrm{~kb}$ of genomic DNA and encodes a 140 amino acid protein. The 420-bp coding region (hatched boxes) is encompassed by exons 3-6, and the untranslated regions (open boxes) consist of exons 1, 2, the $5^{\prime}$ portion of exon 3, and the 3' portion of exon 6 . The start (ATG) and stop (TGA) codons in exons 3 and 6, respectively, are indicated. The typical sequencing chromatograms of healthy control, SEDT patient, and female carrier are shown in B. C. and D. respectively.

tions, splice-site mutations, nonsense mutations, missense mutations, and insertions, are responsible for most cases of SEDT (Xiao et al., 2003; Xiong et al., 2009). To our knowledge, although more than 40 different sequence variations across $S E D L$ have been reported to date, the genotype-phenotype correlation for $S E D L$ mutations remains unclear. Gedeon et al. (2001) suggested that there might be a trend of decreasing severity within the group of patients according to the location of their mutations, $5^{\prime} \rightarrow 3^{\prime}$, along the $S E D L$ gene. In contrast, based on their clinical findings, Shaw et al. (2003) proposed the hypothesis that any mutations would cause a complete loss-of-function effect of the sedlin protein, and the resulting clinical outcomes might be generally the same. The identification of further novel mutations in individuals with SEDT will provide additional evidence for or against the two contrasting hypotheses. In the Chinese family evaluated in the present study, a novel nonsense mutation (c.61G>T) in the $5^{\prime}$ end of $S E D L$ caused a severe SEDT phenotype. Additionally, four other mutations located upstream of intron 3 in $S E D L$, which were identified in five unrelated families, also appeared to result in a severe outcome. A summary of the 5' mutations and the corresponding phenotypes is presented in Table 3 (Gedeon et al., 1999, 2001; Matsui et al., 2001; Gao et al., 2003). Therefore, the trend of increasing severity towards the 5 ' end of the open reading frame (ORF) noted by Gedeon et al. (2001) was also apparent in the reported cases, including the current study.

In this study, the novel nonsense mutation $(\mathrm{c} .61 \mathrm{G}>\mathrm{T})$ in exon 3 of the $S E D L$ gene can be predicted to create a premature translation termination codon (PTC). PTCs have been shown to initiate the degradation of mutant transcripts through the NMD pathway to prevent the possible toxic effects of truncated peptides (Huang and Wilkinson, 2012; Kervestin and Jacobson, 2012; Lin et al., 2012). The nature of the nonsense mutation suggests that the SEDL product, sedlin, would not be produced in the affected individuals. Thus, the severe clinical 
phenotypes might be caused by the complete loss-of-function effect of the sedlin mutation, which needs to be further investigated.

\begin{tabular}{|c|c|c|c|c|c|c|c|c|}
\hline \multirow[t]{2}{*}{ No. } & \multirow{2}{*}{$\begin{array}{l}\text { Gene } \\
\text { region }\end{array}$} & \multirow{2}{*}{$\begin{array}{l}\text { Nucleotide } \\
\text { change }\end{array}$} & \multirow{2}{*}{$\begin{array}{l}\text { Predicted } \\
\text { consequence }\end{array}$} & \multirow{2}{*}{$\begin{array}{l}\text { Ethnic } \\
\text { origin }\end{array}$} & \multicolumn{3}{|c|}{ Clinical features } & \multirow[t]{2}{*}{ Reference } \\
\hline & & & & & $\begin{array}{l}\text { Adult height } \\
(\mathrm{cm})\end{array}$ & $\begin{array}{c}\text { Onset } \\
(\mathrm{yr})\end{array}$ & Severity & \\
\hline 1 & Intron 2 & IVS2-2 A>C & Splicing variant & French & $\mathrm{NA}$ & & & Gedeon et al., 2001 \\
\hline 2 & Intron 2 & IVS2-2 $\mathrm{A}>\mathrm{C}$ & Splicing variant & Chinese & 140 & 8 & $\begin{array}{l}\text { Progressive back pain, severe } \\
\text { scoliosis, short neck, barrel chest }\end{array}$ & Gao et al., 2003 \\
\hline 3 & $\begin{array}{l}\text { Intron 2/ } \\
\text { Exon } 3\end{array}$ & $\begin{array}{l}\text { in2/ex3 } \\
\text { (del1763bp) }\end{array}$ & Gross & Japanese & 145 & NA & $\begin{array}{l}\text { back pain, paravertebral muscle } \\
\text { tenderness }\end{array}$ & Matsui et al., 2001 \\
\hline 4 & Exon 3 & Exon3del & Gross & Australian & 139.3 & 6.5 & $\begin{array}{l}\text { scoliosis, hip pain referred to knees, } \\
\text { back pain, arms extend to knees }\end{array}$ & Gedeon et al., 2001 \\
\hline 5 & Exon 3 & c.53-54delTT & p.F18* & Australian & $137-160$ & 11 & $\begin{array}{l}\text { barrel chest, kyphoscoliosis, and } \\
\text { osteoarthritis affecting the femoral } \\
\text { heads }\end{array}$ & Gedeon et al., 1999 \\
\hline 6 & Exon 3 & c. $61 \mathrm{G}>\mathrm{T}$ & p.E21 * & Chinese & 147 & 10 & $\begin{array}{l}\text { Back pain, hip pain, scoliosis, } \\
\text { barrel chest }\end{array}$ & Present study \\
\hline
\end{tabular}

Mutation numbering is based on cDNA sequences. +1 corresponds to the A of the ATG translation initiation codon. Amino acids are numbered from the translation initiator methionine. $*$ Stop codon. $\mathrm{NA}=$ not available.

The actual function of the sedlin protein is not known, although it is speculated that it might participate in ER-to-Golgi transport as part of a novel, highly conserved multi-protein TRAPP complex, which functions at various steps in intracellular transport (Scrivens et al., 2009; Venditti et al., 2012). Recently, several investigations have aimed to gain insight into the function of the sedlin protein. Choi et al. (2009) suggested that the sedlin mutations S73L, F83S, and V130D cause SEDT by sedlin protein misfolding, whereas the D47Y mutation may influence normal TRAPP dynamics. Jeyabalan et al. (2010) argued that sedlin was present in the nucleus, forms homodimers, and that SEDT-associated mutations cause a loss of interaction with the transcription factors $c-m y c$ promoter-binding protein 1 (MBP1), pituitary homeobox 1 (PITX1), and steroidogenic factor 1 (SF1). Venditti et al. (2012) demonstrated that sedlin controlled the ER export of procollagen by regulating the Sar1 cycle, which might explain the defective chondrogenesis underlying SEDT. In short, SEDT might be caused by derangement in chondrogenesis, reflecting the inability of chondrocytes to properly secrete extracellular matrix components (Venditti et al., 2012).

In conclusion, identification of the novel nonsense mutation $(\mathrm{c} .61 \mathrm{G}>\mathrm{T})$ in the SEDT family has enabled carrier detection, genetic counseling, and prenatal diagnosis. The detailed genotype/phenotype descriptions contribute to completion of the SEDL mutation spectrum. The continued identification of mutations in SEDT patients will greatly assist in the further elucidation of the role of the sedlin protein in normal bone growth.

\section{ACKNOWLEDGMENTS}

Research supported by the National Natural Science Foundation of China (\#30901652) and the Science Natural Science of Jiangsu Province (\#BK2011660). We are indebted to Prof. Zhao-Qi 
Song for his instructions. We thank all members of the family for their cooperation in the study.

\section{Supplementary material}

\section{REFERENCES}

Choi MY, Chan CC, Chan D, Luk KD, et al. (2009). Biochemical consequences of sedlin mutations that cause spondyloepiphyseal dysplasia tarda. Biochem. J. 423: 233-242.

Christie PT, Curley A, Nesbit MA, Chapman C, et al. (2001). Mutational analysis in X-linked spondyloepiphyseal dysplasia tarda. J. Clin. Endocrinol. Metab. 86: 3233-3236.

Cui YX, Xia XY, Bu Y, Zhou GH, et al. (2008). Rapid molecular prenatal diagnosis of spondyloepiphyseal dysplasia congenita by PCR-SSP assay. Genet. Test 12: 533-536.

Fiedler J, Le MM, Mortier G, Heuertz S, et al. (2004). X-linked spondyloepiphyseal dysplasia tarda: Novel and recurrent mutations in 13 European families. Hum. Mutat. 24: 103.

Gao C, Luo Q, Wang HL, Gao XQ, et al. (2003). Identification of a novel mutation IVS2-2A $\rightarrow$ C of SEDL gene in a Chinese family with X-linked spondyloepiphyseal dysplasia tarda. Zhonghua Yi Xue Yi Chuan Xue Za Zhi. 20: 15-18.

Gecz J, Shaw MA, Bellon JR and de Barros LM (2003). Human wild-type SEDL protein functionally complements yeast Trs20p but some naturally occurring SEDL mutants do not. Gene 320: 137-144.

Gedeon AK, Colley A, Jamieson R, Thompson EM, et al. (1999). Identification of the gene (SEDL) causing X-linked spondyloepiphyseal dysplasia tarda. Nat. Genet. 22: 400-404.

Gedeon AK, Tiller GE, Le MM, Heuertz S, et al. (2001). The molecular basis of X-linked spondyloepiphyseal dysplasia tarda. Am. J. Hum. Genet. 68: 1386-1397.

Grunebaum E, Arpaia E, MacKenzie JJ, Fitzpatrick J, et al. (2001). A missense mutation in the SEDL gene results in delayed onset of X linked spondyloepiphyseal dysplasia in a large pedigree. J. Med. Genet. 38: 409-411.

Huang L and Wilkinson MF (2012). Regulation of nonsense-mediated mRNA decay. Wiley Interdiscip. Rev. RNA 3: 807-828.

Jang SB, Kim YG, Cho YS, Suh PG, et al. (2002). Crystal structure of SEDL and its implications for a genetic disease spondyloepiphyseal dysplasia tarda. J. Biol. Chem. 277: 49863-49869.

Jeyabalan J, Nesbit MA, Galvanovskis J, Callaghan R, et al. (2010). SEDLIN forms homodimers: characterisation of SEDLIN mutations and their interactions with transcription factors MBP1, PITX1 and SF1. PLoS One 5: e10646.

Kervestin S and Jacobson A (2012). NMD: a multifaceted response to premature translational termination. Nat. Rev. Mol. Cell Biol. 13: 700-712.

Lin Z, Chen Q, Shi L, Lee M, et al. (2012). Loss-of-function mutations in HOXC13 cause pure hair and nail ectodermal dysplasia. Am. J. Hum. Genet. 91: 906-911.

Liu X, Wang Y, Zhu H, Zhang Q, et al. (2010). Interaction of Sedlin with PAM14. J. Cell Biochem. 109: 1129-1133.

Matsui Y, Yasui N, Ozono K, Yamagata M, et al. (2001). Loss of the SEDL gene product (Sedlin) causes X-linked spondyloepiphyseal dysplasia tarda: Identification of a molecular defect in a Japanese family. Am. J. Med. Genet. 99: 328-330.

Mumm S, Christie PT, Finnegan P, Jones J, et al. (2000). A five-base pair deletion in the sedlin gene causes spondyloepiphyseal dysplasia tarda in a six-generation Arkansas kindred. J. Clin. Endocrinol. Metab. 85: 3343-3347.

Mumm S, Zhang X, Gottesman GS, McAlister WH, et al. (2001). Preonset studies of spondyloepiphyseal dysplasia tarda caused by a novel 2-base pair deletion in SEDL encoding sedlin. J. Bone Miner. Res. 16: 2245-2250.

Savarirayan R, Thompson E and Gecz J (2003). Spondyloepiphyseal dysplasia tarda (SEDL, MIM \#313400). Eur. J. Hum. Genet. 11: 639-642.

Scrivens PJ, Shahrzad N, Moores A, Morin A, et al. (2009). TRAPPC2L is a novel, highly conserved TRAPP-interacting protein. Traffic 10: 724-736.

Shaw MA, Brunetti-Pierri N, Kadasi L, Kovacova V, et al. (2003). Identification of three novel SEDL mutations, including mutation in the rare, non-canonical splice site of exon 4. Clin. Genet. 64: 235-242.

Venditti R, Scanu T, Santoro M, Di TG, et al. (2012). Sedlin controls the ER export of procollagen by regulating the Sar1 cycle. Science 337: 1668-1672.

Xia X, Cui Y, Huang Y, Pan L, et al. (2007). A first familial G504S mutation of COL2A1 gene results in distinctive spondyloepiphyseal dysplasia congenita. Clin. Chim. Acta 382: 148-150.

Xia XY, Cui YX, Huang YF, Pan LJ, et al. (2008a). Molecular prenatal diagnosis in 2 pregnancies at risk for spondyloepiphyseal dysplasia congenita. Clin. Chim. Acta 387: 153-157. 
Xia XY, Cui YX, Huang YF, Pan LJ, et al. (2008b). A novel RNA-splicing mutation in COL1A1 gene causing osteogenesis imperfecta type I in a Chinese family. Clin. Chim. Acta 398: 148-151.

Xia XY, Cui YX, Zhou YC, Zhou X, et al. (2009). A novel insertion mutation in the SEDL gene results in X-linked spondyloepiphyseal dysplasia tarda in a large Chinese pedigree. Clin. Chim. Acta 410: 39-42.

Xiao C, Zhang S, Wang J, Qiu W, et al. (2003). A single nucleotide deletion of 293delT in SEDL gene causing spondyloepiphyseal dysplasia tarda in a four-generation Chinese family. Mutat. Res. 525: 61-65.

Xiong F, Gao J, Li J, Liu Y, et al. (2009). Noncanonical and canonical splice sites: a novel mutation at the rare noncanonical splice-donor cut site (IVS4+1A>G) of SEDL causes variable splicing isoforms in X-linked spondyloepiphyseal dysplasia tarda. Eur. J. Hum. Genet. 17: 510-516.

Zong M, Wu XG, Chan CW, Choi MY, et al. (2011). The adaptor function of TRAPPC2 in mammalian TRAPPs explains TRAPPC2-associated SEDT and TRAPPC9-associated congenital intellectual disability. PLoS One 6: e23350. 